\title{
Paradojas de la globalización alimentaria
}

\section{Paradoxes of food globalization}

Jesús Contreras ${ }^{1}$

La historia de la humanidad ha sido, en buena medida, la de la búsqueda de recursos o soluciones para resolver los problemas del hambre, cuantitativa (alimentos) o cualitativa (nutrientes). Gracias a las tecnologías actuales, podría pensarse que la producción y productividad alimentaria han aumentado de tal manera que el hambre podría haber sido totalmente erradicada. Por otro lado, gracias a la investigación biomédica, la prevención de las enfermedades derivadas de la alimentación es hoy más posible que nunca. Podría decirse que estamos frente a un "nuevo orden alimentario". Sin embargo, a pesar de la sobreabundancia, persiste el hambre; y la ciudadanía, no parece estar convencida de reducir la alimentación a su dimensión nutricional. En efecto, los beneficios de la abundancia alimentaria se hacen menos obvios cuando, por una parte, se pone en duda la calidad de los alimentos producidos y cuando, por otra, se convierte en posible causa de enfermedades y riesgos de diverso alcance. El cambio alimentario tropieza, pues, con una cierta insatisfacción de la ciudadanía confrontada a unos alimentos "industriales", que los encuentra insípidos, faltos del sabor de antaño e, incluso, peligrosos. Ello coincide, paradójicamente, con el aumento de las reglamentaciones sobre higiene y políticas de calidad puestas en marcha por las autoridades políticas y sanitarias. Por otra parte, muchas de las que fueron soluciones alimentarias en el pasado han tenido "efectos colaterales" que hoy parecen inaceptables por razones de salud, de sostenibilidad ambiental o de desigualdad social. Además, los desarrollos recientes de la tecnología o de la industria alimentaria han perturbado la doble función identificadora de lo culinario - la identificación del alimento y la construcción de la identidad del sujeto.

Así, la progresiva globalizaciónalimentaria provoca una "nostalgia" relativa a los "patrimonios culinarios". La cocina constituye un patrimonio cultural. La patrimonialización alimentaria se produce en el contexto del conjunto de las transformaciones socioeconómicas contemporáneas y de sus repercusiones en los comportamientos y en las ideas relativas a la alimentación. Identidad y/o patrimonio son nuevos "recursos" de la modernidad y de usos polivalentes. Ya no se trata de producciones mundiales que pierden progresivamente la huella de su lugar de origen sino de productos que, por el contrario, lo encarnan y se espera de ellos que evoquen un territorio, un paisaje, unas costumbres, una identidad.

Palabras-clave: identidad; patrimonio alimentar; globalización.

Keywords: identity; food heritage; globalization.

1 Antropólogo espanhol, diretor do grupo de estudos e pesquisas Observatorio de la Alimentación (Odela), vinculado à Universitat de Barcelona. Autor de, entre outros livros, Alimentación y cultura: perspectivas antropológicas (2005), publicado em parceria com a antropóloga Mabel Gracia e lançado em português com o título Alimentação, sociedade e cultura (2011), pela Editora Fiocruz. 